\title{
Prevalence and predictive factors of sleep bruxism in children with and without cognitive impairment
}

\section{Cristina Batista Miamoto(a) Luciano José Pereira ${ }^{(b)}$ Maria Letícia Ramos-Jorge(c) Leandro Silva Marques(a)}

(a) Department of Clinical Dentistry, Vale do Rio Verde University - UNINCOR, Três Corações, MG, Brazil.

(b) Departament of Physiology and Pharmacology, Federal University of Lavras - UFLA, Lavras, MG, Brazil.

(c)Department of Pediatric Dentistry, Federal University of Jequitinhonha and Mucuri Valleys - UFVJM, Diamantina, MG, Brazil.

Declaration of Interests: The authors certify that they have no commercial or associative interest that represents a conflict of interest in connection with the manuscript.

\section{Corresponding author:}

Leandro Silva Marques

E-mail: Ismarques.prof@gmail.com

Received for publication on Jun 08,2011 Accepted for publication on Aug 26, 2011

\begin{abstract}
Studies have found a higher prevalence of sleep bruxism (SB) in individuals with cognitive impairment. The aim of this study was to identify the prevalence and factors associated with the clinical manifestation of SB in children with and without cognitive impairment. The sample was made up of 180 individuals: Group 1 - without cognitive impairment; Group 2 - with Down syndrome; Group 3 - with cerebral palsy. Malocclusions were assessed based on the Dental Aesthetic Index (DAI); lip competence was assessed based on Ballard's description. The bio-psychosocial characteristics were assessed via a questionnaire and clinical exam. Statistical analysis involved the chi-square test $(\mathrm{p} \leq 0.05)$ and multivariate logistic regression. The prevalence of bruxism was $23 \%$. There were no significant differences between the groups $(\mathrm{p}=0.970)$. Individuals with sucking habits (OR $[95 \% \mathrm{CI}]=4.44[1.5$ to 13.0$]$ ), posterior crossbite (OR $[95 \% \mathrm{CI}]=3.04$ [1.2 to 7.5]) and tooth wear facets $(\mathrm{OR}[95 \% \mathrm{CI}]=3.32$ [1.2 to 8.7]) had a greater chance of exhibiting SB. Sucking habits, posterior crossbite and tooth wear facets were identified as being directly associated with the clinical manifestations of bruxism.
\end{abstract}

Descriptors: Down Syndrome; Cerebral Palsy; Malocclusion; Sleep Bruxism.

\section{Introduction}

Sleep bruxism (SB) is defined as a parafunctional behaviour of the mandible, characterized by clenching and/or grinding of the teeth. ${ }^{1}$ The aetiology and characteristics of bruxism have not yet been well defined. ${ }^{2}$ However, studies point to different associated risk indicators, such as local, psychological, genetic, neurological, systemic and social factors. ${ }^{2-5}$ The prevalence of SB ranges from $3 \%$ to $90 \%$ in adults and from $7 \%$ to $88 \%$ in children. ${ }^{6}$

The consequence most commonly associated with SB is tooth wear, which may compromise the dentition in a localized or generalized manner. Headaches, temporomandibular disorders, joint pain and pain during mastication are also associated with the manifestation of SB. Severe bruxism for a prolonged period of time can result in muscle hypertrophy (massester and/or temporalis). The treatment of acute conditions involves physiotherapy, "biofeedback" electromyography and medication for the relief of anxiety and sleep improvements. Long-term approaches include forms of reducing stress, changes in lifestyle, the control of habits, 
myorelaxation plates and night-time dental guards to protect the teeth and mastication system. ${ }^{7-9}$

Only a few studies have investigated the diverse aspects related to SB in patients with physical and/ or cognitive impairments. ${ }^{10-13}$ Recent studies found a higher prevalence in individuals with Down syndrome when compared to individuals without cognitive impairment. Additionally, SB appeared to affect individuals with cerebral palsy twice as much as control individuals. Thus, understanding the biopsychosocial aspects associated with the manifestation of SB is a determining factor in planning strategies to aid healthcare professionals in dealing with these conditions.

The aims of the present study were to identify the prevalence and possible determinants of SB in individuals without cognitive impairment, with Down syndrome and with cerebral palsy.

\section{Methodology}

The participants in the present study were individuals (with Down syndrome or cerebral palsy) who were receiving medical-hospital care at four specialized institutions. A control group without cognitive or physical impairments was selected from among patients awaiting orthodontic treatment at a Dental School.

The following inclusion criteria were required for participation in the present study: not having been submitted to any type of orthodontic intervention and confirmed diagnosis of the condition. The project received approval from the Ethics Committee. The parents/guardians signed terms of informed consent.

The data were collected via a questionnaire and a clinical examination of the individuals. For the diagnosis of malocclusion, the criteria of the Dental Aesthetic Index (DAI) were used, which furnishes four outcome possibilities:

- normal occlusion or mild malocclusion, for which treatment is unnecessary (DAI $<25)$;

- defined malocclusion, for which treatment is elective (DAI = 26 to 30 );

- severe malocclusion, for which treatment is highly desirable (DAI = 31 to 35 ); and

- very severe or debilitating malocclusion, for which treatment is necessary $(\mathrm{DAI} \leq 36) .{ }^{14}$

This variable was characterized as: absent, moderate or severe.

Malocclusions were clinically classified as Class I, Class II and Class III, based on the Angle classification. Crossbite was also included and identified during the physical examination. Lip competence was assessed based on Ballard's criteria: mandible in physiological resting position and lips in juxtaposition (sealed), with no contraction of the orbicular muscles of the mouth or the mentalis. ${ }^{15}$ Lip incompetence was recorded if the child needed to vigorously contract the orbicular muscles of the mouth and the mentalis in order to seal the lips. Drooling was assessed based on the classification drafted by Thomas-Stonell and Greenberg (1988). ${ }^{16}$ Drooling was evaluated since research has demonstrated a significant relationship between sialorrhoea during sleep and bruxism. ${ }^{5}$ Records from the institutions and reports from parents/guardians were also assessed.

The signs and symptoms of SB were recorded taking into account: sibling or parental reports of grinding sounds (at least three times a week), the presence of shiny and polished facets on the incisors and/or first permanent molars (primarily based on palatal surface and incisal edges and working cusps, respectively), taking into account the time of eruption. Wear facets on deciduous teeth were not considered. The presence of SB was confirmed by both parental reports and the presence of tooth wear, since the latter is a cumulative sign. ${ }^{4}$

Statistical analysis involved chi-square and Fisher's exact tests $(p \leq 0.05)$ for evaluating the association between independent variables on the prevalence of SB in the overall sample and in each of the groups separately as well. Multivariate logistic regression was employed in order to find predictive factors associated with SB in the overall sample.

\section{Results}

The prevalence of SB in the overall sample was $23 \%$. There was a $23 \%$ prevalence of bruxism among the individuals with Down syndrome; 25\% prevalence among those with cerebral palsy; and 
Table 1 - Distribution of independent variables in relation to SB.

\begin{tabular}{|c|c|c|c|}
\hline & \multicolumn{2}{|c|}{ Sleep bruxism (SB) } & \multirow{2}{*}{$p$-value } \\
\hline & Absent n (\%) & Present n (\%) & \\
\hline \multicolumn{4}{|c|}{ Groups } \\
\hline Control & $45(75.5)$ & $15(25.0)$ & \multirow{3}{*}{0.970} \\
\hline Cerebral palsy & $46(76.7)$ & $14(23.3)$ & \\
\hline Down syndrome & $46(76.7)$ & $14(23.3)$ & \\
\hline \multicolumn{4}{|c|}{ Gender } \\
\hline Male & $65(77.4)$ & $19(22.6)$ & \multirow{2}{*}{0.709} \\
\hline Female & $72(75.0)$ & $24(25.0)$ & \\
\hline \multicolumn{4}{|c|}{ Age } \\
\hline More than 10 years & $69(78.4)$ & $19(21.6)$ & \multirow{2}{*}{0.479} \\
\hline 3 to 10 years & 68 (73.9) & $24(26.1)$ & \\
\hline \multicolumn{4}{|c|}{ Behaviour } \\
\hline Calm & $116(74.8)$ & $39(25.2)$ & \multirow{2}{*}{0.319} \\
\hline Agitated & 21 (84.0) & $4(16.0)$ & \\
\hline \multicolumn{4}{|c|}{ Premature birth } \\
\hline No & 109 (76.2) & $34(23.8)$ & \multirow{2}{*}{0.673} \\
\hline Yes & $24(72.7)$ & 9 (27.3) & \\
\hline \multicolumn{4}{|c|}{ Sucking habits } \\
\hline No & 127 (79.9) & $32(20.1)$ & \multirow{2}{*}{0.001} \\
\hline Yes & $10(47.6)$ & $11(52.4)$ & \\
\hline \multicolumn{4}{|c|}{ Worn facets } \\
\hline No & 116 (79.5) & $30(20.5)$ & \multirow{2}{*}{0.029} \\
\hline Yes & $21(61.8)$ & $13(38.2)$ & \\
\hline \multicolumn{4}{|c|}{ Facial type } \\
\hline Long face & $35(70.0)$ & $15(30.0)$ & \multirow{3}{*}{0.083} \\
\hline Average & $86(81.9)$ & $19(18.1)$ & \\
\hline Short face & $16(64.0)$ & $9(36.0)$ & \\
\hline
\end{tabular}

$23 \%$ prevalence among those with malocclusion (23\%). Table 1 shows the frequency distribution of the independent variables in relation to the dependent variable (the presence or absence of SB).

Having cognitive impairment was not predictive of SB $(\mathrm{p}=0.970)$. Sucking habits, limited mouth opening, tooth wear facets, facial type and posterior crossbite achieved $p$-values of $\leq 0.20$ and were therefore included in the multivariate regression model. This model revealed that individuals with sucking habits $(\mathrm{p}=0.007)$ had a fourfold greater chance of exhibiting SB. Moreover, the presence of tooth wear
Table 1 (continued)

\begin{tabular}{|c|c|c|c|}
\hline \multicolumn{4}{|c|}{ Breathing } \\
\hline Nasal & $100(78.1)$ & 28 (21.9) & \multirow{2}{*}{0.320} \\
\hline Mouth & $37(71.2)$ & $15(28.8)$ & \\
\hline \multicolumn{4}{|c|}{ Drooling } \\
\hline Absent & $115(77.7)$ & $33(22.3)$ & \multirow{3}{*}{0.375} \\
\hline Moderate & $10(76.9)$ & $3(23.1)$ & \\
\hline Severe & $12(63.2)$ & $7(36.8)$ & \\
\hline \multicolumn{4}{|c|}{ Type of malocclusion } \\
\hline Class I & $52(76.5)$ & $16(23.5)$ & \multirow{3}{*}{0.361} \\
\hline Class II & $51(81.0)$ & $12(19.0)$ & \\
\hline Class III & $34(69.4)$ & $15(30.6)$ & \\
\hline \multicolumn{4}{|c|}{ Posterior crossbite } \\
\hline Absent & $103(79.8)$ & $26(20.2)$ & \multirow{2}{*}{0.062} \\
\hline Present & $34(66.7)$ & $17(33.3)$ & \\
\hline \multicolumn{4}{|c|}{ Severity of malocclusion } \\
\hline Absent or mild & $54(79.4)$ & $14(20.6)$ & \multirow{3}{*}{0.258} \\
\hline Moderate & $22(84.6)$ & $4(15.4)$ & \\
\hline Severe & 61 (70.9) & $25(29.1)$ & \\
\hline \multicolumn{4}{|c|}{ Caries } \\
\hline Absent & $54(77.1)$ & $16(22.9)$ & \multirow{3}{*}{0.772} \\
\hline 1 to 2 teeth with cavities & $43(78.2)$ & $12(21.8)$ & \\
\hline 3 to 7 teeth with cavities & $40(72.7)$ & $15(27.3)$ & \\
\hline
\end{tabular}

facets $(\mathrm{p}=0.015)$ and posterior crossbite $(\mathrm{p}=0.017)$ increased the risk of SB by approximately threefold (Table 2).

The influence of independent variables in each group showed that sucking habits were associated with SB in both cognitive impairment condition groups and that worn facets were only associated with SB in the Down syndrome group. For the controls, facial type and posterior crossbite were associated with SB (Table 3).

\section{Discussion}

The occurrence of sleep bruxism has been reported with varying frequencies in the general population. ${ }^{69}$ In the present sample, the conditions of Down syndrome or cerebral palsy had no influence over the presence of bruxism when compared to a group of individuals without cognitive impairment 
Table 2 - Multivariate logistic regression (forward stepwise procedure) for SB.

\begin{tabular}{|c|c|c|c|c|}
\hline & \multicolumn{4}{|c|}{ Sleep bruxism } \\
\hline & $\begin{array}{c}\text { Non-adjusted OR } \\
(95 \% \mathrm{CI})\end{array}$ & $\mathrm{p}$-value & $\begin{array}{l}\text { Adjusted OR } \\
(95 \% \mathrm{Cl})\end{array}$ & $\mathrm{p}$-value \\
\hline \multicolumn{5}{|c|}{ Sucking habit } \\
\hline No & 1.00 & & 1.00 & \\
\hline Yes & $4.36(1.71-11.8)$ & 0.002 & $4.44(1.50-13.09)$ & 0.007 \\
\hline \multicolumn{5}{|c|}{ Worn facets } \\
\hline No & 1.00 & & 1.00 & \\
\hline Yes & 2.39 (1.08-5.33) & 0.032 & 3.32 (1.26-8.73) & 0.015 \\
\hline \multicolumn{5}{|c|}{ Posterior crossbite } \\
\hline Absent & 1.00 & & 1.00 & \\
\hline Present & $1.98(0.96-4.08)$ & 0.064 & 3.04 (1.22-7.57) & 0.017 \\
\hline \multicolumn{5}{|c|}{ Facial type } \\
\hline Long face & 1.00 & & 1.00 & \\
\hline Average & $0.52(0.24-1.13)$ & 0.097 & $0.44(0.17-1.11)$ & 0.084 \\
\hline Short face & 1.31 (0.47-3.63) & 0.600 & $1.64(0.39-6.95)$ & 0.501 \\
\hline
\end{tabular}

$(\mathrm{p}=0.970)$. Previous studies reported that individuals with cognitive impairment are more prone to this parafunction due to spasticity (an increase in muscle tone at the time of muscle contraction caused by an abnormal neurological condition - the spastic muscles are more resistant to contraction than normal muscles and also require more effort to relax and remain contracted for a period of time). ${ }^{10-13}$ However, recent studies have found that the prevalence of SB is similar between such individuals and control individuals matched for age. ${ }^{6,17}$ As a result of different study methods, clinical criteria and the populations studied, the reported prevalence of SB varies significantly. Another factor linked to this variability is related to the diagnostic criteria for bruxism through reports from the individual himself/herself, clinical exams and reports from parents and/or partners. Children and individuals with special needs have difficulty identifying and/or reporting teeth grinding habits coherently. Thus, SB in the present study was diagnosed from the reports of parents/guardians and clinical evaluations. ${ }^{9,18}$

Tooth wear facets were significantly predictive of SB in the present study, especially in Down syndrome patients, thereby corroborating the notion that one of the most common consequences of clenching and/or grinding the teeth is localized and generalized tooth wear. ${ }^{6}$ The diagnosis of tooth wear facets should be considered with caution. Although it can be objectively measured, it may not directly reflect the degree of current $\mathrm{SB}$, as individuals can exhibit the effects of past habits that are no longer present at the time of evaluation, which could lead to an overestimation of prevalence. Likewise, individuals who recently acquired the habit may not yet exhibit signs of tooth wear, which could lead to an underestimation of bruxism. ${ }^{19,20}$

In the present study, sucking habits and posterior crossbite increased the chance of an individual exhibiting SB by approximately threefold. The evaluation of associations between variables in separate groups indicated that the former variable was more important in cognitively impaired children, whereas the latter was more important in control subjects. The relationship between parafunctional habits and malocclusion is well established in the literature. ${ }^{21}$ Sucking habits are related to an increase in overjet and a Class II molar pattern, which has been demonstrated to be related to SB..$^{21,22}$ However, the relationship between malocclusion and SB remains controversial. In a previous study involving 975 individuals between 7 and 19 years of age, no causal relationship was found between malocclusions and the presence of this parafunction. ${ }^{23}$ On the other 
Table 3 - Distribution of independent variables in relation to SB in each of the groups separately.

\begin{tabular}{|c|c|c|c|c|c|c|}
\hline & \multicolumn{6}{|c|}{ Sleep bruxism } \\
\hline & \multicolumn{2}{|c|}{ Control } & \multicolumn{2}{|c|}{ Cerebral palsy } & \multicolumn{2}{|c|}{ Down syndrome } \\
\hline & $\begin{array}{c}\text { Absent } \\
\mathrm{n}(\%)\end{array}$ & $\begin{array}{c}\text { Present } \\
\mathrm{n}(\%)\end{array}$ & $\begin{array}{c}\text { Absent } \\
\mathrm{n}(\%)\end{array}$ & $\begin{array}{c}\text { Present } \\
\mathrm{n}(\%)\end{array}$ & $\begin{array}{c}\text { Absent } \\
\mathrm{n}(\%)\end{array}$ & $\begin{array}{c}\text { Present } \\
\mathrm{n}(\%)\end{array}$ \\
\hline Gender & \multicolumn{2}{|c|}{$p=0.755^{F}$} & \multicolumn{2}{|c|}{$p=0.744^{c}$} & \multicolumn{2}{|c|}{$p=0.818^{c}$} \\
\hline Male & 15 (78.9) & 4 (21.1) & $22(78.6)$ & $6 \quad(21.4)$ & $28 \quad(75.7)$ & 9 (24.3) \\
\hline Female & $30 \quad(73.2)$ & 11 (26.8) & 24 (75) & $8(25)$ & 18 (78.3) & $5 \quad(21.7)$ \\
\hline Age & \multicolumn{2}{|c|}{$p=0.136^{c}$} & \multicolumn{2}{|c|}{$p=0.136^{c}$} & \multicolumn{2}{|c|}{$p=0.064^{F}$} \\
\hline$>10$ years & 25 (83.3) & $5(16.7)$ & 22 (73.3) & $8 \quad(26.7)$ & $28 \quad(87.5)$ & 4 (12.5) \\
\hline$\leq 10$ years & $20 \quad(66.7)$ & 10 (33.3) & 24 (80) & $6(20)$ & 18 (64.3) & $10(35.7)$ \\
\hline Behaviour & \multicolumn{2}{|c|}{$*$} & \multicolumn{2}{|c|}{$p=0.112^{F}$} & \multicolumn{2}{|c|}{$p=0.582^{F}$} \\
\hline Calm & 45 (75) & 15 (25) & 28 (70) & 12 (30) & $43 \quad(78.2)$ & 12 (21.8) \\
\hline Agitated & - & - & $18(90)$ & $2(10)$ & $3(60)$ & $2(40)$ \\
\hline Premature Birth & \multicolumn{2}{|c|}{$p=0.987^{F}$} & \multicolumn{2}{|c|}{$p=0.738^{F}$} & \multicolumn{2}{|c|}{$p=0.291^{F}$} \\
\hline No & 42 (75) & 14 (25) & 32 (74.4) & 11 (25.6) & $35(79.5)$ & 9 (20.5) \\
\hline Yes & $2(66.7)$ & 1 (33.3) & 13 (81.3) & $3(18.8)$ & 9 (64.3) & $5 \quad(35.7)$ \\
\hline Sucking habits & \multicolumn{2}{|c|}{$p=0.205^{F}$} & \multicolumn{2}{|c|}{$p=0.036^{F}$} & \multicolumn{2}{|c|}{$p=0.036^{F}$} \\
\hline No & 37 (78.7) & 10 (21.3) & $45 \quad(80.4)$ & 11 (19.6) & $45 \quad(80.4)$ & 11 (19.6) \\
\hline Yes & $8 \quad(61.5)$ & $5 \quad(38.5)$ & $1 \quad(25)$ & $3 \quad(75)$ & $1 \quad(25)$ & $3(75)$ \\
\hline Worn facets & \multicolumn{2}{|c|}{$p=0.566^{F}$} & \multicolumn{2}{|c|}{$p=0.511^{F}$} & \multicolumn{2}{|c|}{$p=0.002^{F}$} \\
\hline No & 42 (73.7) & 15 (26.3) & 34 (79.1) & 9 (20.9) & 40 (87) & $6(13)$ \\
\hline Yes & $83(100)$ & $\begin{array}{ll}0 & (0)\end{array}$ & 12 (70.6) & $5 \quad(29.4)$ & $6(42.9)$ & $8 \quad(57.1)$ \\
\hline Facial type & \multicolumn{2}{|c|}{$p=0.036^{c}$} & \multicolumn{2}{|c|}{$p=0.836^{c}$} & \multicolumn{2}{|c|}{$p=0.102^{c}$} \\
\hline Long face & $8(57.1)$ & $6(42.9)$ & 24 (77.4) & 7 (22.6) & $3(60)$ & $2(40)$ \\
\hline Average & 37 (82.2) & $8(17.8)$ & 21 (75) & $7 \quad(25)$ & $28(87.5)$ & $4 \quad(12.5)$ \\
\hline Short face & $0 \quad(0)$ & $1(100)$ & $1(100)$ & $0 \quad(0)$ & $15(65.2)$ & 8 (34.8) \\
\hline Breathing & \multicolumn{2}{|c|}{$p=0.258^{F}$} & & $75^{c}$ & & $68^{F}$ \\
\hline Nasal & 43 (76.8) & $13(23.2)$ & $21(75)$ & $7 \quad(25)$ & $36(81.8)$ & $8 \quad(18.2)$ \\
\hline Mouth & $2(50)$ & $2(50)$ & $25(78.1)$ & 7 (21.9) & $10(62.5)$ & $6(37.5)$ \\
\hline Drooling & & & & $70^{\mathrm{CL}}$ & & $37^{\mathrm{CL}}$ \\
\hline Absent & 45 (75) & $15(25)$ & $25(86.2)$ & $4(13.8)$ & 45 (76.3) & $14(23.7)$ \\
\hline Moderate & - & - & $9(75)$ & $3(25)$ & $1(100)$ & $\begin{array}{ll}0 & (0)\end{array}$ \\
\hline Severe & - & - & $12(63.2)$ & $7 \quad(36.8)$ & - & - \\
\hline Type of malocclusion & & $86^{c}$ & & $32^{c}$ & & $06^{c}$ \\
\hline Class I & $24(77.4)$ & $7 \quad(22.6)$ & $16(66.7)$ & 8 (33.3) & $12(92.3)$ & $1 \quad(7.7)$ \\
\hline Class II & $19(76)$ & $6(24)$ & $20(90.9)$ & $2 \quad(9.1)$ & $12(75)$ & $4(25)$ \\
\hline Class III & $2(50)$ & $2(50)$ & $10(71.4)$ & 4 (28.6) & $22(71)$ & 9 (29) \\
\hline Posterior crossbite & & $19^{F}$ & & $64^{F}$ & & $44^{c}$ \\
\hline Absent & $42(80.8)$ & $10(19.2)$ & $39(79.6)$ & $10(20.4)$ & $22(78.6)$ & $6(21.4)$ \\
\hline Present & $3(37.5)$ & $5(62.5)$ & 7 (63.6) & $4 \quad(36.4)$ & $24(75)$ & $8(25)$ \\
\hline
\end{tabular}


Table 3 (continued)

\begin{tabular}{|c|c|c|c|c|c|c|}
\hline Severity of malocclusion & \multicolumn{2}{|c|}{$p=0.189^{C L}$} & \multicolumn{2}{|c|}{$p=0.852^{C L}$} & \multicolumn{2}{|c|}{$p=0.486^{c}$} \\
\hline Absent or mild & 37 (78.7) & 10 (21.3) & $15(78.9)$ & $4(21.1)$ & $24 \quad(85.7)$ & $4(14.3)$ \\
\hline Moderate & $4 \quad(66.7)$ & $2(33.3)$ & $2(66.7)$ & 1 (33.3) & 8 (88.9) & $1(11.1)$ \\
\hline Severe & $4 \quad(57.1)$ & 3 (42.9) & 29 (76.3) & $9(23.7)$ & $14 \quad(60.9)$ & $9(39.1)$ \\
\hline Caries & \multicolumn{2}{|c|}{$p=0.127^{c L}$} & \multicolumn{2}{|c|}{$p=0.456^{c L}$} & \multicolumn{2}{|c|}{$p=0.819 \mathrm{cL}$} \\
\hline Absent & 14 (77.8) & $4 \quad(22.2)$ & $20(74.1)$ & $7 \quad(25.9)$ & $20(80)$ & $5(20)$ \\
\hline 1 to 2 teeth with cavities & $21 \quad(87.5)$ & $3(12.5)$ & 10 (71.4) & $4(28.6)$ & $12(70.6)$ & $5(29.4)$ \\
\hline 3 to 7 teeth with cavities & $10(55.6)$ & $8(44.4)$ & $16(84.2)$ & $3(15.8)$ & $14(77.8)$ & $4(22.2)$ \\
\hline
\end{tabular}

${ }^{C}$ chi square test, ${ }^{\mathrm{F}}$ Fisher's exact test, ${ }^{\mathrm{CL}}$ chi square test with linear trend, *chi square test not performed.

hand, an epidemiological study involving 2529 individuals found that occlusal alterations such as the loss of posterior teeth, the incisor relationships and posterior crossbite were significantly associated with the presence of bruxism. ${ }^{24}$ Moreover, Sari and Sonmez found a positive association between an overjet greater than $6 \mathrm{~mm}$, an overbite greater than $5 \mathrm{~mm}$ and posterior crossbite and SB in children with mixed dentition. ${ }^{25}$

Altered contact between the occlusal surfaces of the teeth during the movements of the mastication is believed to create a greater tendency towards mandibular deviation, thereby favouring SB. ${ }^{7}$ However, occlusal factors have been contested and psychological aspects are considered to be the principal factors involved in the occurrence of bruxism. ${ }^{2}$ Such factors should not be overlooked in individuals with Down syndrome or cerebral palsy, as these individuals have a high degree of dependence and frequent conditions of anxiety, which could trigger SB. ${ }^{26}$ Behaviour was assessed in the present study, but no significant association with SB was found, which may explain the similarity in the prevalence of SB between the patients with special needs and the controls. It is important to stress that the individuals with cognitive impairment may not have had a greater prevalence of parafunctional habits due to the fact that they frequented specialized care centres. In such places, individuals have access to multidisciplinary treatment with physiotherapists, speech therapists, physicians, dentists, psychologists and occupational therapists, who considerably contribute towards the prevention, identification and control of behaviours or dysfunctions and provide information to parents and families. ${ }^{27,28}$

The importance of the present study resides in highlighting the fact that a significant portion of individuals with Down syndrome and cerebral palsy exhibit parafunctional habits. The maintenance of such habits from childhood into adulthood may compromise health, leading to problems linked to the temporomandibular joint, facial muscles, tooth wear, periodontal disease and even tooth loss stemming from trauma. ${ }^{29}$

\section{Conclusions}

The prevalence of bruxism in individuals with Down syndrome and cerebral palsy was similar to that found in individuals without cognitive impairment (approximately 24\%). The predictive factors for SB in the population studied were the presence of sucking habits, posterior crossbite and tooth wear facets.

\section{Acknowledgments}

The authors are grateful to the Research Fostering Agency of the State of Minas Gerais (FAPEMIG) and the National Council of Science and Technology Development (CNPq) for grants awarded to LSM and LJP, respectively. 


\section{References}

1. Serra-Negra JM, Paiva SM, Seabra AP, Dorella C, Lemos BF, Pordeus IA. Prevalence of sleep bruxism in a group of Brazilian schoolchildren. Eur Arch Paediatr Dent. 2010 Aug;11(4):1925.

2. Negoro T, Briggs J, Plesh O, Nielsen I, McNeill C, Miller AJ. Bruxing patterns in children compared to intercuspal clenching and chewing as assessed with dental models, electromyography, and incisor jaw tracing: preliminary study. ASDC J Dent Child. 1998 Nov-Dec;65(6):449-58, 438.

3. Bayar GR, Tutuncu R, Acikel C. Psychopathological profile of patients with different forms of bruxism. Clin Oral Investig. 2011. DOI: 10.1007/s00784-010-0492-9.

4. Castelo PM, Barbosa TS, Gavião MB. Quality of life evaluation of children with sleep bruxism. BMC Oral Health. 2010 Jun;10:16.

5. Simões-Zenari M, Bitar ML. Factors associated to bruxism in children from 4-6 years. Pro Fono. 2010 OctDec;22(4):465-72.

6. López-Pérez R, López-Morales P, Borges-Yáñez SA, Maupomé G, Parés-Vidrio G. Prevalence of bruxism among Mexican children with Down syndrome. Downs Syndr Res Pract. 2007 Jul;12(1):45-9.

7. Barbosa TS, Miyakoda LS, Pocztaruk RL, Rocha CP, Gavião MB. Temporomandibular disorders and bruxism in childhood and adolescence: review of the literature. Int J Pediatr Otorhinolaryngol. 2008 Mar;72(3):299-314.

8. Magnusson T, Egermarki I, Carlsson GE. A prospective investigation over two decades on signs and symptoms of temporomandibular disorders and associated variables. A final summary. Acta Odontol Scand. 2005 Apr;63(2):99-109.

9. Castelo PM, Gavião MB, Pereira LJ, Bonjardim LR. Relationship between oral parafunctional/nutritive sucking habits and temporomandibular joint dysfunction in primary dentition. Int J Paediatr Dent. 2005 Jan;15(1):29-36.

10. Bell EJ, Kaidonis J, Townsend GC. Tooth wear in children with Down syndrome. Aust Dent J. 2002 Mar;47(1):30-5.

11. Borea G, Magi M, Mingarelli R, Zamboni C. The oral cavity in Down's syndrome. J Pedod. 1990 Spring;14(3):139-40.

12. Peres AC, Ribeiro MO, Juliano Y, César MF, Santos RC. Occurrence of bruxism in a sample of Brazilian children with cerebral palsy. Spec Care Dentist. 2007 Mar-Apr;27(2):73-6.

13. Ortega AO, Guimarães AS, Ciamponi AL, Marie SK. Frequency of parafunctional oral habits in patients with cerebral palsy. J Oral Rehabil. 2007 May;34(5):323-8.

14. Cons NC, Jenny J, Kohout FJ, Freer TJ, Eismann D. Perceptions of occlusal conditions in Australia, the German Democratic Republic and the United States of America. Int Dent J. 1983 Jun;33(2):200-6.

15. Ballard MB. A statistical study of 200 cases with ten or more years interval between pregnancies. Bull Sch Med Univ Md. 1953 Apr;38(2):66-73.
16. Morales Chávez MC, Nualart Grollmus ZC, Silvestre-Donat FJ. Clinical prevalence of drooling in infant cerebral palsy. Med Oral Patol Oral Cir Bucal. 2008 Jan 1;13(1):E22-6.

17. Buckley S. Teeth grinding. Downs Syndr Res Pract. 2007 Jul;12(1):16.

18. Cheifetz AT, Osganian SK, Allred EN, Needleman HL. Prevalence of bruxism and associated correlates in children as reported by parents. J Dent Child (Chic). 2005 MayAug;72(2):67-73.

19. Vanderas AP, Manetas KJ. Relationship between malocclusion and bruxism in children and adolescents: a review. Pediatr Dent. 1995 Jan-Feb;17(1):7-14.

20. Baba K, Haketa T, Clark GT, Ohyama T. Does tooth wear status predict ongoing sleep bruxism in 30-year-old Japanese subjects?. Int J Prosthodont. 2004 Jan-Feb;17(1):39-44.

21. Singh SP, Utreja A, Chawla HS. Distribution of malocclusion types among thumb suckers seeking orthodontic treatment. J Indian Soc Pedod Prev Dent. 2008;26 Suppl 3:S114-7.

22. Henrikson T, Ekberg EC, Nilner M. Symptoms and signs of temporomandibular disorders in girls with normal occlusion and Class II malocclusion. Acta Odontol Scand. 1997 Aug;55(4):229-35.

23. Demir A, Uysal T, Guray E, Basciftci FA. The relationship between bruxism and occlusal factors among seven- to 19-yearold Turkish children. Angle Orthod. 2004 Oct;74(5):672-6.

24. Bernhardt O, Gesch D, Splieth C, Schwahn C, Mack F, Kocher T, et al. Risk factors for high occlusal wear scores in a population-based sample: results of the Study of Health in Pomerania (SHIP). Int J Prosthodont. 2004 May-Jun;17(3):333-9.

25. Sari S, Sonmez H. The relationship between occlusal factors and bruxism in permanent and mixed dentition in Turkish children. J Clin Pediatr Dent. 2001 Spring;25(3):191-4.

26. Cooper SA, Smiley E, Jackson A, Finlayson J, Allan L, Mantry $\mathrm{D}$, et al. Adults with intellectual disabilities: prevalence, incidence and remission of aggressive behaviour and related factors. J Intellect Disabil Res. 2009 Mar;53(3):217-32.

27. Rossi R, Blonna D, Germano M, Castoldi F. Multidisciplinary investigation in Down syndrome: bear in mind. Orthopedics. 2008 Mar;31(3):279.

28. Minnes P, Steiner K. Parent views on enhancing the quality of health care for their children with fragile $\mathrm{X}$ syndrome, autism or Down syndrome. Child Care Health Dev. 2009 Mar;35(2):250-6.

29. Camparis CM, Siqueira JT. Sleep bruxism: clinical aspects and characteristics in patients with and without chronic orofacial pain. Oral Surg Oral Med Oral Pathol Oral Radiol Endod. 2006 Feb;101(2):188-93. 